\title{
Climate Change Impacts on Rural Based Women: Emerging Evidence on Coping and Adaptation Strategies in Tsholotsho, Zimbabwe
}

Keith Phiri

\author{
Lecturer, Department of Development Studies, Lupane State University, Zimbabwe \\ Email: kephirih@gmail.com \\ Sibonokuhle Ndlovu \\ Lecturer, Department of Development Studies, Lupane State University, Zimbabwe \\ Email: boomagwala@gmail.com \\ Tanyaradzwa Bonga Chiname
}

Student, Lupane State University, Zimbabwe

Doi:10.5901/mjss.2014.v5n23p2545

\begin{abstract}
Climate change is one of the major challenges that are confronting developing countries. Rural women in Zimbabwe are one of the most hard hit populace groups. The study sought to investigate how rural women are affected by climate change in relation to their livelihoods. It also explores women's perception of climate change and the effects of those perceptions on adapting to climate change. Emphasis is made on the effects of climate change on crop production, livestock production and water sources focusing on Tsholotsho District in Zimbabwe. The study used a qualitative approach to obtain data on the effects of climate change. One of the major findings of the study was that the impact of climate change undermines women's livelihoods which are rain-fed thus leading to accelerated food insecurity problems and heightened impoverishment. The paper concludes that women in rural areas must be prioritized in development programming especially in agriculture to ameliorate impending and inevitable climate change induced food insecurity.
\end{abstract}

Keywords: Climate Change, Livelihoods, Adaptation, Zimbabwe

\section{Introduction}

There is emerging empirical evidence that the implications of climate change in Zimbabwe will be dire. Recent studies show that the number of years with below average rainfall is increasing. For example, Zhakata (2008) cited in International Crops Research Institute for the Semi-Arid-Tropics (ICRISAT) (2008) notes there are signs of gradual warming in both summer and winter temperatures and models suggest that south-west Zimbabwe's second largest city (Bulawayo) will experience a minimum rise in daily temperatures of $2.7^{\circ} \mathrm{C}$ before the end of the $21^{\text {st }}$ century. Masendeke (2008) cited in International Crops Research Institute for the Semi-Arid-Tropics (ICRISAT) (2008) expresses similar sentiments arguing that farmers have noticed changes in the quantity and quality and efficacy of rainfall. He adds that farmers have also noticed environmental changes which include the drying up of wetlands, ponds, pans and riverbeds. Certain grass species that used to be found in wetlands are disappearing together with related small insect species. Climatic changes have also made it difficult for the communities to master and follow their traditional ways of weather prediction. The rainfall patterns have not been uniform and predictable. The pointers used to determine rainfall patterns are no longer considered reliable.

Gender issues have been rarely addressed in the context of the damaging effects of climate change. Women's roles are not adequately recognized or accounted for in climate change mitigation and adaptation efforts, in national and global climate negotiation talks or in the context of natural disasters influenced or exacerbated by climate change. The vulnerability of women to the effects of climate change is mainly because of their over-dependence on natural resources, their responsibility for water and food procurement and their increased risk exposure during times of disasters and severe weather crises (UNDP, 2009).

Climate change represents a profound challenge to the livelihoods of women, as it has negatively affected their 
sources of income and means of production that enable them to provide for their families. This is due to the fact that women in a patriarchal nation such as Zimbabwe which celebrates male dominance evidenced particularly by land ownership, have limited adaptive capacity. This research is one which was motivated by an interest in the effects of climate change on women's livelihoods. The study sought to answer the following questions; how has climate change affected women's livelihoods in Tsholotsho? What are the existing coping and adaptation strategies used by women in response to climate change?

\section{Review of Relevant Literature}

Climate change threatens everyone, but does not threaten all people equally (Patterson 2009). Women are disproportionately affected by natural disasters as they experience higher rates of mortality, morbidity and post disaster diminishment in their livelihoods. Furthermore, Denton (2002) cited by Masika (2002) argues that women are more vulnerable than men to climate change as they are reported to be the majority amongst the poorest and most disadvantaged groups in society. In addition, women in developing countries are responsible for climatically sensitive tasks, such as securing food, water and energy, which ensures food security and household well-being. The disadvantaged position of women means greater difficulty in coping with disasters. Overall, climate change is seen as magnifying existing inequalities, reinforcing the disparity between women and men in their vulnerability and capability to cope with climate change. It is for this reason that scholars like Dankelman (2002) suggest that there is need to consider studies of the relationship between gender and the environment in order to determine the gender dimension of climate change. Women in the course of their daily tasks have developed an intimate knowledge of the prevailing climatic conditions. However, their knowledge and capabilities have not been fully recognized and they often face social and economic exclusion in development issues (Kipuri and Ridgewell, 2008).

It should be highlighted that climate change culminates in varying negative impacts on the weather patterns and the environment from which women heavily rely on for their livelihoods. These negative impacts are inclusive of increased temperatures, low, erratic and unreliable rainfall, or increased rainfall that may lead to flooding and general unpredictability of rainfall timing which directly affects crop development in a negative manner hence crop destruction which more often than not results in food insecurity. Devereux (2007) propounds that climate change has negative impacts on weather patterns, which increase the frequency and intensity of climate related hazards and hence the level and patterns of often interrelated risks, exacerbating levels of vulnerability for the poor and excluded people.

Climate change is to blame for the current food insecurity crisis in Zimbabwe. Heltberg (2008) argues that "areas that have received increased rainfall have had heightened crop destruction, owing to water logging of soils which has led to the leaching of soil nutrients leading to poor crop production. Again in areas with increased rainfall, crop diseases mainly caused by fungi which thrives in humid conditions has surely contributed to the destruction of both animals and crops hence food insecurity." On the same note, it should be pointed out that because of food insecurity induced by climate change; malnutrition has also emerged as crop diversification which caters for the production of a variety of plants offering different nutrients has also been destroyed. Mitchel (2008) quotes Odingo (2006) arguing that climate change will make it impossible for the world to achieve the Millennium Development Goals. Poverty is bound to increase. Food insecurity is bound to get worse. Odingo's (2006) assertion bears testimony to the fact that climate change makes the dream of attaining the reduction of poverty by $50 \%$ by 2015 an ambitious and far-fetched one.

\section{Research Methodology}

The research used a qualitative approach to explore women's experiences of climate change in Tsholotsho District. The thrust of the study was to understand how climate change has impacted on women's livelihoods in terms of crop production, livestock production and water resources. Moreover, the study sought to establish the perceptions of women on climate change and how they are adapting to it. Three focus group discussions, consisting of 15 women totaling to 45 participants were carried out. Purposive sampling was used to select the participants. Particular attention was paid to ensure that ward councilors, kraal heads and local farmers constituted the discussion. The focus group discussions sought to obtain data on women's perceptions about climate change and how the phenomenon had affected their livelihoods. Furthermore; in-depth interviews were conducted with relevant stakeholders to the question of climate change in Tsholotsho. In this study key informants, including Officers from Agricultural Extension Services Department, Rural District Council and the Organisation of Rural Associations for Progress, were purposively selected. They were selected on the basis that they are knowledgeable about the effects of climate change on women's livelihoods. The study also employed observation as a data collection tool. Using this approach the researchers systematically observed the state of 
the ecological system pertaining to the grazing lands, crops and water sources amongst other things.

\section{Climate Change and Women's Livelihoods: Findings}

\subsection{Effects of Climate Change on Crop Production}

An absolute $100 \%$ of the respondents lamented the fact that flooding in some parts of the district accounted for reduced food crop productivity hence their heightened food insecurity. An AGRITEX Tsholotsho officer commented that;

... floods affect crop production in that the excess water for plants brought on by flooding causes the plants to be weakened and thus becoming susceptible to insect and microbial infections.

Furthermore, respondents asserted that forceful water movement uprooted the plants thus leading to crop destruction. Moreover, Adger (2000) observes that floods as a direct result of climate change have also brought misery to women as they have resulted in harvest failures. Evenson (1999) asserts that floods have a leaching effect on soils, and this has led to the washing down of the soil nutrients to a level where they cannot be accessed by plants hence crop failure. Floods also destroy the quality of the soil hence reduced productivity. One other negative effect of floods are that they make it possible for fungal diseases to thrive and destroy plants given that this type of disease emerges and intensifies in humid conditions offered by floods. Poor seed germination and stunted growth is a direct result of climate change with its associated calamities such as erratic low rainfall and increased temperatures. Furthermore AGRITEX Tsholotsho (2013) asserts that up to 30\% cereal crop is lost to wilting. Another 15\% is lost to floods. Both the in-depth and focus group respondents concurred with AGRITEX in stressing that crops such as maize, millet, sorghum are weakened by little or excess rains and are prone to microbial infections and insect pests.

\subsection{Effects of Climate Change on Livestock Production}

Temperature extremes affect general livestock performance. Respondents from both the in-depth interviews and FDGs concurred that high temperatures promote pests such as ticks and mites and hence reducing the general immunity of the animal. One of the respondents observed that;

Ticks cause poor fertility on livestock and their general appearance becomes unpleasant such that when one decides to sell them, the market value is greatly reduced...

For the women without the capital for purchasing animal medication, livestock loss is exacerbated. Sentiments from respondents and the key informants were that high temperatures encourage higher rates of evapotranspiration and hence a rapid diminishing of water in the livestock body systems. Again livestock productivity has been affected in that the grazing lands for feeding have significantly reduced in size and quality of grass. One of the respondents from the focus group discussion highlighted that;

\footnotetext{
As far as grazing pastures are concerned oh!! That is disaster! For the past years it has been disastrous. We ended up relocating our cattle to some plots in Nyamandlovu. Many people lost all their cattle. The few cattle you see here are the ones that were relocated to Nyamandlovu. We are likely to relocate some cattle this year if the situation does not improve.
}

Notably, poor feeding patterns for livestock has resulted in reduced milk and meat production hence affecting food security for the rural populace in the district. Again because of poor food intake for livestock, particularly labor providing animals such as donkeys and cattle, labor supply is affected for women, especially considering the fact that generally women lack the necessary stamina to carry out some chores. It is worth noting that in all the focus group discussions women concurred that water scarcity brought on by climate change accounts for more than half of livestock death hence contributing to food insecurity and heightened poverty for women.

\subsection{Effects of Climate Change on Water Sources}

A majority $80 \%$ of the respondents from both the focus group discussions and the in-depth interviews concurred with AGRITEX's notion that climate change accounts for reduced water supply for animal and human use. This notion is in line 
with observations by Brody et al (2008) who articulate that climate change has led to water scarcity as a result of the drying up of water sources. This has consequently compelled women to walk longer distances in search of water. Such long distances have negative effects on the health of women (Adger 2000). Drinking water for both humans and animals has drastically been reduced. The respondents indicated that the commencement of the rainy season is now a cause for concern given that it is unpredictable and often delayed hence prolonging the recurring droughts. Most rivers are often dry because of the low rainfall. Water tables are receding and this has had significant detrimental effects on accessing borehole water. In the focus group discussions, women echoed that reduced water supply is posing as a setback in their vegetable gardening. Swampy areas and streams of water are also drying up at an alarmingly fast rate. Wells are also on the verge of drying up. A crystal shining example of a dried up river as a result of climate change is the Gwaai River.

\subsection{Seasonal Livelihoods Affected by Climate Change}

More than half of the female respondents from the focus group discussions were in agreement with AGRITEX Tsholotsho's observation of the fact that seasonal mopane worm (caterpillars) gathering, preservation and selling is under the climate change threat hence impoverishing the women. Reduced rainfall accounts for reduced mopane worm availability. One of the respondents from the FGDs highlighted that;

I was born in 1942. There were lots of mopane worms when we grew up, there was no hunger, we used to have them for relish and everything was good. When we went to school our fees were paid using mopane worms income. We got married still depending on mopane worms for our living, we sent our children to school using income from mopane worms. Mopane worms have become fewer ... sometimes we would not have them for about five years ...But because of the lack of rain... we do not know if this is the cause of the non-availability of the worms.

Consequently this limits food access opportunities for the families depending on the Mopane worms for relish. Furthermore, the women who generate their incomes from selling the Mopane worms are further impoverished by climate change in this manner.

The respondents also pointed out that thatch grass harvesting and selling has also been affected by climate change. Rural communities use grass for thatching their huts as some of the households do not afford zinc and asbestos sheets. Respondents during an FGD concurred that;

Currently we are no longer able to raise income through the sale of thatch grass. Thatch grass has always been one important way of raising income to cover various household needs. Nowadays the quality of the grass is poor and the quantities have been reduced.

As such some women sell the grass as a livelihood activity. This is said to be so in the sense that reduced rainfall affects the growth and quality of the grass to be sold. This therefore has negative implications on the income generating projects for the women in the district.

\section{Adaptive Strategies to Climate Change: Findings}

\subsection{Crops}

With the realization that climate change is a phenomenon which is projected to exist for a long period with its adverse effects, people have seen the need to employ adaptive strategies as a means of cushioning themselves against the effects of climate change. Varying adaptive strategies were highlighted as being employed by women in the district. The table below contains the strategies identified by the respondents of the focus group discussions as being employed for crop productivity.

Figure 1. Table showing adaptive strategies used by women on crop production (Source: Survey data)

\begin{tabular}{|l|c|}
\hline Adaptive Strategy & Adopters \\
\hline Crop Rotation & $20 \%$ \\
\hline Delayed Planting & $50 \%$ \\
\hline Minimum Tillage & $80 \%$ \\
\hline Crop Diversification & $20 \%$ \\
\hline Contour Ploughing & $10 \%$ \\
\hline Drought Resistant Crops & $100 \%$ \\
\hline
\end{tabular}


The table above illustrates the adaptive strategies and the rates at which they are being employed by the various respondents. The Organization of Rural Associations for Progress (2013) concurs with the responses attained from the focus group discussions with reference to their assertion that in Tsholotsho, most women have shifted from producing maize as the main crop to pearl millet and sorghum as these are drought tolerant small grain plants. One of the elderly respondents asserted that;

My grandchild, there is limited rainfall in this area, those who grow maize are wasting their time, my household now depends on pearl millet and sorghum as these are drought resistant.

It is of essence to highlight the fact that ORAP operates nutrition gardens for women in the study district. These gardens focus on growing drought resistant crops. Moreover, ORAP is involved in the implementation of programs such as the Farmer Field Schools (FFS). These train and give out information to women on the best farming methods in response to climate change. The FFS's advocate for the production of small grain drought resistant crops with the capacity of producing food as compared to sensitive crops such as maize. FAO (2000) posits that in the midst of climate change, planting drought resistant crops has emerged as one of the major adaptive strategies for rural women. FAO (2000) further points out that, women have shifted from planting water sensitive crops to drought resistant crops as these have the ability to resist weather hazards. This is done in a bid to improve food security.

It also emerged from the research that minimum tillage is also an adaptive strategy for crop production in Tsholotsho. During a focus group discussion, a certain woman named Bonga (not real name) was asked to state her adaptive farming method and to subsequently explain the reason behind the choice of the farming method, she articulated that;

My child, I do not have cattle for ploughing therefore I have resorted to minimum tillage, after tilling the land I plant and weed later, in this way I harvest some grains.

The articulation by the respondent points to the fact that she has shifted from conventional farming methods to minimum tillage as an adaptive strategy that seeks to conserve soil moisture. The in-depth interview with the AGRITEX official indicated that in its outreach programmes in Tsholotsho it has emphasized the advantages of minimum tillage and continues to do so. The respondent also highlighted that local farmers including women have taken up their advice.

Delayed planting is one other adaptive strategy employed in a bid to save plants from total destruction by the hazards associated with climate change. A certain Ma Ndlovu (name not real) asserted that;

\section{In the past years I have realized that the commencement of the first rains is now delayed therefore I also practice delayed planting.}

This assertion points to the fact that women are now making use of the delayed planting measure as an adaptive strategy. From the interview with the ORAP official it was revealed that the rationale behind delayed planting is based on the time factor. This is so in the sense that farming is now a gambling activity characterized with risks of crop loss and farmers await the first rains to come before ploughing and planting regardless of the fact that the traditional period of ploughing would have elapsed. FAO (2000) also supports the view that delayed planting is an effective adaptive strategy to climate change by stating that delayed planting is advantageous in that planting at the onset of the coming of rains ensures germination of the seeds.

Crop rotation is one other strategy utilized by the women of Tsholotsho as an adaptive strategy. Responses from the focus group discussions and the in-depth interviews revealed that women were embracing and making use of crop rotation. The study revealed that the rationale behind using crop rotation is for using legume plants as means of restoring nitrogen to the soil hence nitrifying the soils for better crop production. It is of essence highlighting the fact that FAO (2000) also views crop rotation as an advantageous adaptive strategy with the advantage of nitrifying the soils for women lacking the capital for purchasing inorganic fertilizers.

Crop diversification is another adaptive strategy practiced in the district as is evidenced by the responses from both the in-depth interviews and the focus group discussions. Responses concurred with the observation by AGRITEX Tsholotsho (2013) that crop diversification reduces the risk of losing out on all crops once a weather hazard hits. One 51 year old woman explained during an FGD;

We no longer know what to plant because the rain is unpredictable. For survival we have switched to drought resistant seed varieties. We are now engaging in multiple and intercropping as a way of trying our luck. 
Responses from the field work highlighted that women were planting a range of crops such as water melons, round nuts, ground nuts, maize, sorghum and millet amongst a host of other crops.

Contour ploughing proved to be an unpopular adaptive strategy amongst women. This was said to be the case because contour ploughing demands a lot of labor, which apparently is in short supply in the district given that most males have migrated to South Africa. When asked why the women were not using contour ploughing, a certain MaSibanda (name not real) asserted that;

Making ridges is a cumbersome task, but there are a few people who do make ridges.

The above quotation when interpreted means that there are some who implement contour ploughing, though it is a cumbersome task. The insight bears testimony to the fact that women are using contour ploughing as an adaptive measure, though it is done so at a disappointingly low scale. AGRITEX Tsholotsho (2013) asserted that contour ploughing is implemented as a measure to conserve water for plants. FAO (2000) conforms to the view by AGRITEX Tsholotsho (2013) of the fact that contour ploughing is a highly effective in conserving water.

\subsection{Livestock}

ORAP (2013) notes that, women in the district have shifted from the production of cattle to small livestock production inclusive of goats and sheep. This is due to the fact that goats and sheep are drought resistant animals. The responses from the focus group discussions depicted that there was a shift from the production of cattle to that of sheep and goats as these are drought resistant. Moreover AGRITEX Tsholotsho (2013) asserts that the shift has been due to the fact that most women have been taught by NGOs such as ORAP to shift to the production of these animals. Figure 2 below shows varying livestock production patterns in the district.

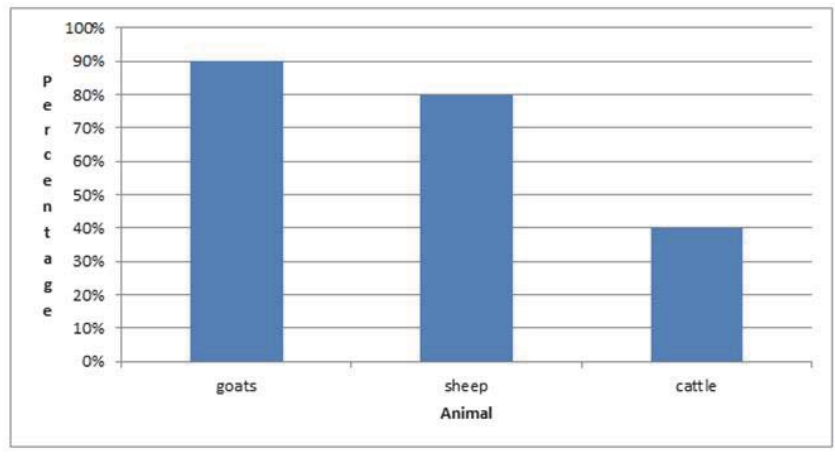

Figure 2: Graph showing shift from cattle production to goat and sheep production (Source: Survey data)

Figure 2 shows that $90 \%$ of the women engaged in goat production, $80 \%$ in sheep production while a low $40 \%$ focused on cattle production. The percentages above bear testimony to the fact that women are largely concentrating on the production of small livestock. ORAP (2013) articulates that women embraced their small livestock programs hence the shift. The shift was also motivated by the realization that cattle production was no longer viable, seeing as most cattle were perishing due to heat stress.

\subsection{Water Supply}

In a bid to conserve water, respondents from the focus group discussions and the in-depth interviews asserted that roof water harvesting is the major adaptive strategy employed by women. Women conserve water in a bid to avoid walking long distances in search of water. The conserved water is used for watering vegetable gardening and for animals to drink. The communities have also resorted to drilling of deep boreholes as the water supply lasts longer as compared to wells and the rivers. The respondents indicated that;

We used to rely on shallow wells and rivers for our water supply. This has drastically changed as the wells and the rivers easily dry up. We have now resorted to boreholes as our major source of water. 
AGRITEX Tsholotsho (2013) further pointed out that in response to water shortages deep boreholes are being drilled to overcome the challenge of receding water tables which have brought about the challenge of water supply.

\section{Migration as a Result of Climate Change}

Migration is one other adaptive strategy popular in Tsholotsho. It is worth noting that because of the low produce of farming, women have resorted to migration in search of better incomes and jobs, particularly to South Africa and Botswana. The emigrants remit money to their families through the cross border drivers popularly referred to as "omalayitsha". The remittances are used for meeting basic needs such as food and school fees. AGRITEX Tsholotsho (2012) affirmed that climate change in Zimbabwe underpins particularly rural-urban and international migration. This is so in the sense that in a patriarchal nation such as Zimbabwe, it is expected of men to be the breadwinners and providers of their families, unfortunately in the midst of climate change which has seriously undermined agricultural productivity men have not been able to fulfill their obligations hence they have been compelled to migrate to other areas in search of employment and better incomes. Consequently, the women who have remained in the rural homes take up the responsibility of breadwinners, which proves to be a tough task given that climate change is and continues to wreck havoc in their livelihood activities such as farming. It should also be highlighted that much as migration is undertaken as an adaptive strategy to climate effect on agriculture, it also has its detrimental effect such as those of making the distanced couples susceptible to HIV and AIDS through sexual multiple partnership.

One respondent from the FDGs highlighted that mass migration of especially young people was spurred on by climate change, especially recurrent droughts. The remittances they send have played a pivotal role in sustaining communities in Tsholotsho. Findings revealed that investments made at home through remittances are not only relied on in times of need, but are also meant to sustain migrants and their families when they eventually return either from Botswana or South Africa. Migrants also invest in houses, solar power, boreholes and means of transport like bicycles and scotch carts. These findings echo Maphosa (2004) who notes that remittances contribute significantly to the improvement of the livelihoods of the receiving households.

\section{Conclusion}

The study concludes that the impacts of climate change on women are serious as they are directly related to their livelihoods. The multi-faceted environmental and agricultural crisis faced by these women through climate change is ghastly to bear. The findings indicate that women in the district are crippled by reduced food reserves, scarce water sources and depleting livestock. Women are also grappling with massive migration of men which is increasing their domestic tasks. However, the women in Tsholotsho have adapted to the negative ripple effects of climate change through various measures like planting of drought resistant crops, contour ploughing and crop rotation among others. Keeping drought resistant animals like goats and sheep is also another adaptive strategy in addition to water harvesting and reliance on remittances from migrants.

\section{References}

Agricultural, Technical and Extension Services Tsholotsho (2012) Report on Rainfall patterns in Tsholotsho, AGRITEX Tsholotsho Agricultural, Technical and Extension Services Tsholotsho (2013) Report on Crop and Livestock Production in Tsholotsho, AGRITEX Tsholotsho

Brody, A., Demetriades, J. and Esplen, E., (2008) Gender and Climate Change: Mapping the linkages- A Scoping study on knowledge and Gaps, Report prepared for the UK Department for International Development, University of Sussex: Institute of Development studies

Dankelman, I. (2002) Climate change: Learning from gender analysis and women's experience of organizing for sustainable development, Gender and Development, 10:2, 21-29

Masika, R. (ed.) (2002) Gender, Development and Climate change, Oxfam, Oxford

Devereux, S. and Collbacks, S. (2007) Review of Evidence Gaps on the effectiveness and Impacts of DFID supported Pilot Transfer Schemes, DFID Evaluation Working Paper, London

Evenson, R. and Siegel, M. (1999) 'Gender and Agricultural Extension in Burkina Faso'. Indiana University Press 46(1):75-92.

Food and Agriculture Organisation (2000). 'Climate-smart Agriculture: Policies, Practices and Financing for food Security, Adaptation and Mitigation', Technical input for The Hague Conference onAgriculture, Food Security and Climate Change. FAO. Rome, OctNov 2000

Heltberg, R., Jorgenson, S. and Seigal, P. (2008) Climate Change for Social Protection in Africa, World Bank Working Paper Series

Kipuri, N. and Ridgewell, A. (2008) A double blind: the exclusion of pastoralists' women in the East and Horn of Africa, Minority rights 
Group International, London

Maphosa, F. (2004) The impact of remittances from Zimbabweans working in South Africa on rural livelihoods in the Southern Districts of Zimbabwe. CODESRIA, Dakar

International Crops Research Institute for the Semi-Arid-Tropics (ICRISAT) (2008) Building adaptive capacity to cope with increasing vulnerability due to climate change, International Crops Research Institute for the Semi-Arid-Tropics, Andhra Pradesh

Mitchell, T., Sabates-Wheeler, R., Devereux, S., Tanner, T., Davies, M. and Leavy, J. (2008) Rural disaster risk-poverty interface, Background paper for Global Assessment Report on Disaster Risk Reduction 2009, United Nations International Strategy for Disaster Reduction, Geneva.

United Nations Development Programme (UNDP 2009) Gender and climate change: Impact and adaptation. IRADe. Available online: http://www.csd-i.org/. Accessed on 4 July, 2014) 